\title{
Atherosclerosis imaging with intravascular ultrasound
}

\section{Validating acquisition and measurement tools to assure meaningful results}

\author{
Paul Schoenhagen
}

Published online: 23 September 2006

(C) Springer Science+Business Media B.V. 2006

\section{Erratum to: Int J Cardiovasc Imaging DOI 10.1007/s10554-006-9104-9}

In the original publication of this editorial comment, the 1st author's name of the original article has been misspelled. The correct text and reference are given below.

In response to the article by Hartmann et al. Dedicated calibration formulas permit correction of differences between measurements by different IVUS devices as demonstrated in atherosclerotic human coronary arteries in vitro (DOI 10.1007/ s10554-006-9092-9).

\section{Reference}

1. Hartmann M, von Birgelen C, Mintz GS, Deppermann N, Dirsch O, Stoel MG, van Houwellingen GK, Louwerenburg HW, Verhorst PMJ, Erbel R (2006) Dedicated calibration formulas permit correction of differences between measurements by different IVUS devices as demonstrated in atherosclerotic humen coronary arteries in vitro. Int $\mathrm{J}$ Cardiovasc Imaging (Epub ahead of print, April 29)

The online version of the original article can be found at http://www.dx.doi.org/10.1007/s10554-006-9104-9

P. Schoenhagen $(\bowtie)$

Department of Radiology, Section of Cardiovascular Imaging and Department of Cardiovascular Medicine, The Cleveland Clinic Foundation, Desk Hb-6, 9500

Euclid Avenue, Cleveland, OH 44195, USA

e-mail: schoenp1@ccf.org 